\title{
Micropropagation of an Elite F1 Watermelon (Citrullus lanatus) Hybrid from the Shoot Tip of Field Grown Plants
}

\author{
Mohammad Khalekuzzaman ${ }^{1,2}$, Mst. Marufa Khatun ${ }^{2}$, Mohammad Harunur Rashid ${ }^{3}$, Md. \\ Mominul Islam Sheikh ${ }^{4}$, Shamima Akhtar Sharmin ${ }^{5}$ and Iftekhar Alam ${ }^{5 *}$ \\ ${ }^{I}$ Department of Life Science; Pohang University of Science and Technology; Pohang 790-784; Republic of Korea. \\ ${ }^{2}$ Department of Genetic Engineering and Biotechnology; ${ }^{3}$ Institute of Biological Sciences; Rajshahi University; \\ Rajshahi 6205; Bangladesh. ${ }^{4}$ Department of Environmental Forest Products; ${ }^{5}$ Division of Applied Life Science \\ (BK21 Program); Gyeongsang National University; Jinju 660-701; Republic of Korea
}

\begin{abstract}
The aim of this work was to develop a protocol for rapid micropropagation of an elite F1 hybrid watermelon cultivar using shoot tip of field-grown plants. Maximum frequency (73\%) of shoot tip showed growth response in MS medium supplemented with $5 \mathrm{mg} \mathrm{l}^{-1}$ benzyl adenine (BA) and $0.1 \mathrm{mg} \mathrm{l}^{-1}$ indole-3 acetic acid (IAA). Upon transfer to cytokinin-enriched medium, the cultures produced multiple shoots and $2.0 \mathrm{mg} \mathrm{l}^{-1}$ BA was optimum in this respect. Addition of gibberellic acid $\left(G A_{3}\right)$ in the multiplication medium resulted in better growth of shoots. Rooting rate was $100 \%$ when shoots were obtained from second subculture were cultured in medium with $1.0 \mathrm{mg} \mathrm{l}^{-1}$ indole-3 butyric acid (IBA). The shoots produced more roots with increasing number of subcultures. About $72 \%$ of the regenerated plantlets acclimatized successfully and survived in the soil condition.
\end{abstract}

Key words: In vitro, watermelon, micropropagation, hybrid vigor

\section{INTRODUCTION}

Watermelon (Citrullus lanatus) is an economically important major fruit grown in the warmer region of the world and ranked sixth in world production of fruit crop. It is globally popular as sweet cool dessert and as cooked vegetables (Moerman 1998). It is an excellent source of vitamin C. Red-fleshed watermelon contains significant amounts of lycopene, a carotenoid pigment, which is a highly efficient free radical scavenger (Perkins-Veazie et al. 2006). High dietary lycopene consumption (4 $\mathrm{mg}$ or more/day) may be beneficial in reducing the incidence of prostate and oral cancers and in the prevention of oxidative damage to the cells (Mohanty et al. 2006; Zhao et al. 2006; Mayne et al. 2004). Tomatoes and tomato products provide most of the dietary intake of lycopene in Western diets. However, red-fleshed watermelon contains more lycopene per unit fresh weight than fresh tomatoes and is equally bioavailable to humans (Edwards et al. 2003). Watermelon flesh has ingredients that deliver Viagra-like effects to the body's blood vessels and may even increase libido (Patil 2008). Watermelon is also a rich source of (non-essential) amino acids such as citrulline (Rimando and Perkins-Veazie 2005). Citrulline is an efficient hydroxyl radical scavenger and a strong antioxidant (Fang et al. 2002).

Excessive number of seeds in watermelon flesh is an undesirable trait. Fruits of interploid hybrids are virtually seedless and sweeter in taste. Tetraploid

\footnotetext{
*Author for correspondence: alami@gnu.ac.kr
} 
plants are commonly sterile and yielded lower number of seeds per fruit. Therefore, rapid improvements of the watermelon cultivars are difficult through conventional breeding. Genetic approaches such as tissue culture and biotechnology offer potential routes of improving the fruit harvest by offering higher quality products, seedless fruit or generating somaclonal variants, with improved resistance to biotic or abiotic stresses (Compton et al. 2004). The use of shoot tip explants for rapid clonal propagation has potential application for the propagation of diploid as well as F1 hybrid breeding lines. The clonal propagation is the favorite method for many species, because it allows the production of more uniform offsprings (Radmann et al. 2011). In addition, an efficient in vitro regeneration system is essential for utilizing the gene transfer technology (Ulisses et al. 2010). The use of many triploid watermelon cultivars showed difficulties in their seed germination. High seed cost of hybrid cultivars is generally associated with difficulties in obtaining a sufficient number of tetraploid plants as they exhibit low fertility and generally required at least 8-10 years of self pollination before enough plants are obtained for commercial triploid seed production (Compton and Gray 1993). Micropropagation of hybrid cultivars has potential use in the vegetable industry as it 'fix' hybrid vigor especially when seeds cost high price and low germination rate. Thus, development of a commercially feasible micropropagation system for triploid and tetraploid watermelon would reduce the production cost and increase the availability of seedless watermelon lines to the growers. Plant regeneration from cotyledon, hypocotyls and seedling shoot apices has been reported in watermelon (Chaturvedi and Bhatnagar 2001; Compton and Gray 1993; Compton et al. 2004; Dong and Jia 1998). In this work, a rapid micropropagation protocol of an elite hybrid watermelon cultivar from field-grown explants was developed.

\section{MATERIALS AND METHODS}

\section{Plant material and establishment of aseptic cultures}

Watermelon shoot apices were collected from a commercial field of a F1 hybrid population (cultivar 'Bengal Tiger'). After removing the large leaves, shoot tips were thoroughly washed in $1 \%$ (v/v) solution of Savlon ${ }^{\circledR}$ (contains $0.1 \%$ chlorhexidine $\mathrm{HCl}$; ACI, Bangladesh) with two drops of Tween-20 for 20 min, followed by rinsing with sterile distilled water. All the subsequent operations were carried out inside a laminar airflow cabinet. Surface sterilization was carried out with $0.1 \%(\mathrm{w} / \mathrm{v})$ mercuric chloride solution for 5 min after a brief rinse in $90 \%$ ethanol for 30 seconds. After washing for five times with sterile distilled water, the tips were slightly trimmed at the cut-end to expose the fresh tissue, and planted on different nutrient media. Different kinds of growth regulators, namely benzyl adenine (BA), kinetin (Kin), 2-isopentenyladenine (2ip), indole3 -acetic acid (IAA), indole-3 butyric acid (IBA), napthalene acetic acid (NAA) and gibberellic acid $\left(\mathrm{GA}_{3}\right)$ were tested in MS basal medium (Murashige and Skoog 1962) for shoot growth and multiplication from the initial explants.

\section{Physical culture condition}

The $\mathrm{pH}$ of the tissue culture media were adjusted to 5.8 with $0.1 \mathrm{~N} \mathrm{NaOH}$ or $0.1 \mathrm{~N} \mathrm{HCI}$. The media were gelled with $0.7 \%(\mathrm{w} / \mathrm{v})$ agar. Finally, media were sterilized at $121^{\circ} \mathrm{C}$ for 20 min under 1.06 $\mathrm{kgcm}^{-2}$ pressures. The cultures were incubated in a growth chamber at $25 \pm 1^{\circ} \mathrm{C}$ under $16 \mathrm{~h}$ photoperiod regimes provided by cool white fluorescent lights with $40-45 \mu \mathrm{mol} \mathrm{m} \mathrm{m}^{-2} \mathrm{~s}^{-1}$ illumination (Alam et al. 2010a).

\section{Rooting and transplantation to soil condition}

For root induction, in vitro grown shoots $(\sim 3 \mathrm{~cm}$ in length) were excised, and transferred to the MS medium containing different concentrations of NAA or IBA (Table 3). Four-week-old rooted shoots were acclimatized as described previously (Alam et al. 2010a). Briefly, the plantlets with well-developed roots (4-6 roots/shoot) were washed carefully to remove agar and then transferred to the pots containing a mixture of autoclaved vermiculite, perlite and garden soil (4:1:4). The pots were covered with polythene bags to maintain high humidity for 6-7 days. The plantlets were maintained in a growth chamber at $25 \pm 1^{\circ} \mathrm{C}$ under $16 \mathrm{~h}$ illumination (145-150 $\mu \mathrm{mol} \mathrm{m} \mathrm{m}^{-2} \mathrm{~s}^{-1}$ ) with fluorescent lamps. The bags were progressively opened weekly. After 10-15 days, the polythene bags were removed and the acclimatized plants were transferred to a shaded area under natural condition. 


\section{Statistical analysis}

For each experiment, 15-20 explants were used and each experiment was repeated twice. Standard error of the mean was calculated and represented as bars in the graph. All the investigated parameters were analyzed using the analysis of variance (ANOVA) and significance level was determined at $p<0.05$. Significant differences among the mean values were tested using Duncan's Multiple Range Test (DMRT).

\section{RESULTS AND DISCUSSION}

The shoot apices cultured on media supplemented with different concentrations of $\mathrm{BA}$ in combination with IAA showed different response during primary establishment. New growth was visible with unfurling of leaves. The explants were considered to be established when the leaf blades were expanded accompanied with elongation of petioles and internodes within 2-3 weeks of culture initiation. The survival rate of explants at $0.1 \mathrm{mg}^{-1}$ IAA increased significantly with increasing level of BA. Maximum number of surviving explants (73\%) and growing cultures $(60 \%)$ were recorded at $5 \mathrm{mg} \mathrm{l}^{-1} \mathrm{BA}$ and $0.1 \mathrm{mg} \mathrm{l}^{-1}$ IAA (Table 1). A combination of cytokinin and auxin in regenerating shoots has been described earlier (Dibax et al. 2010). In some cases, a little amount of callus was found at the base of the explant. Within four weeks, a large number of axillary and adventitious buds were developed from the nodal and internodes areas of the explant. Later on, significant morphological changes were observed and the shoot buds attained a maximum size and started sprouting.

Table 1 - Effect of BA and IAA on the establishment of shoot apices. Each value is an average of two replications and 16 explants were used for each replication. Mean separation in columns by Duncan's Multiple Range Test

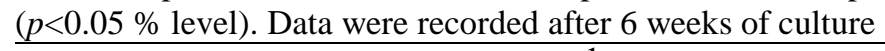

\begin{tabular}{cccc}
\hline \multicolumn{2}{c}{ Growth regulators $\left(\mathbf{m g ~ I}^{\mathbf{1}}\right)$} & \multicolumn{2}{c}{ Shoot apices response } \\
\hline BA & IAA & Survival $(\%)$ & Growth $(\%)$ \\
\hline 1 & 0.1 & $41 \mathrm{~d}$ & $22 \mathrm{c}$ \\
3 & 0.1 & $54 \mathrm{~b}$ & $30 \mathrm{~b}$ \\
5 & 1.0 & $73 \mathrm{a}$ & $60 \mathrm{a}$ \\
1 & 0.5 & $50 \mathrm{bc}$ & $27 \mathrm{bc}$ \\
3 & 0.5 & $40 \mathrm{~d}$ & $20 \mathrm{c}$ \\
5 & 0.5 & $42 \mathrm{~cd}$ & $23 \mathrm{bc}$ \\
\hline
\end{tabular}

After six weeks of culture in establishment medium, the basal portion of the explants were cut and transferred to the multiplication media for multiple shoot production. Among the three cytokinins tested, BA was suitable for multiple shoot formation (Table 2). Maximum number of shoots within a month of transfer was obtained in medium containing $2 \mathrm{mg} \mathrm{l}^{-1}$ BA (Fig. 1b).

Although extensive multiplication occurred, the shoots were compact with short internodes and small leaves. The inclusion of $\mathrm{GA}_{3}$ in the proliferation medium resulted elongation of shoots
(3-4 $\mathrm{cm}$ in length) with larger leaves and decreased number of shoots. Although the number of shoots decreased significantly, the plants could be handled more easily than those plants grown in without $\mathrm{GA}_{3}$. Positive effect of $\mathrm{GA}_{3}$ on stem elongation has also been reported in many plant species, including sweet potato castor and Operculina turpethum (Alam et al. 2010a, b, c). The regenerated shoots were excised and transferred to either rooting medium for adventitious rooting or transferred to same multiplication medium for further multiplication. 
Table 2 - Effect of cytokinins and $\mathrm{GA}_{3}$ on the multiplication and growth of shoot after transferring from establishment media. Data were recorded after 4 weeks of culture. Each value is an average of three replications and 8 explants were used for each replication. F values with degrees of freedom (DF) are indicated

\begin{tabular}{|c|c|c|c|}
\hline \multicolumn{2}{|c|}{ Growth regulators $\left(\mathrm{mg} \mathrm{l}^{-1}\right)$} & \multirow[t]{2}{*}{ No. of shoots/explant } & \multirow[t]{2}{*}{ Shoot length $(\mathrm{cm})$} \\
\hline Kin & & & \\
\hline 1 & 0 & $6.3 \pm 1.4$ & $2.1 \pm 0.2$ \\
\hline 1 & 1 & $4.3 \pm 0.8$ & $4.0 \pm 0.2$ \\
\hline 2 & 0 & $8.4 \pm 1.1$ & $3.2 \pm 0.3$ \\
\hline 2 & 1 & $7.2 \pm 0.9$ & $4.0 \pm 0.3$ \\
\hline \multicolumn{4}{|l|}{$\mathrm{BA}$} \\
\hline 1 & 0 & $8.2 \pm 1.1$ & $2.0 \pm 0.5$ \\
\hline 1 & 1 & $5.4 \pm 0.4$ & $3.9 \pm 0.1$ \\
\hline 2 & 0 & $16.0 \pm 0.8$ & $2.4 \pm 0.2$ \\
\hline 2 & 1 & $10.1 \pm 0.9$ & $3.8 \pm 0.2$ \\
\hline \multicolumn{4}{|l|}{ 2ip } \\
\hline 1 & 0 & $3.1 \pm 0.9$ & $2.9 \pm 0.2$ \\
\hline 1 & 1 & $3.0 \pm 0.7$ & $4.0 \pm 0.4$ \\
\hline 2 & 0 & $5.1 \pm 0.8$ & $3.9 \pm 0.3$ \\
\hline 2 & 1 & $4.2 \pm 1.0$ & $4.0 \pm 0.3$ \\
\hline Item & DF & $\mathrm{F}$ & $\mathrm{F}$ \\
\hline Replication & 2 & $4.89 \mathrm{NS}$ & $3.54 \mathrm{NS}$ \\
\hline Cytokinins & 2 & $18.77 * * *$ & $5.00 \mathrm{NS}$ \\
\hline GA3 & 1 & $4.10 *$ & $3.87 *$ \\
\hline
\end{tabular}
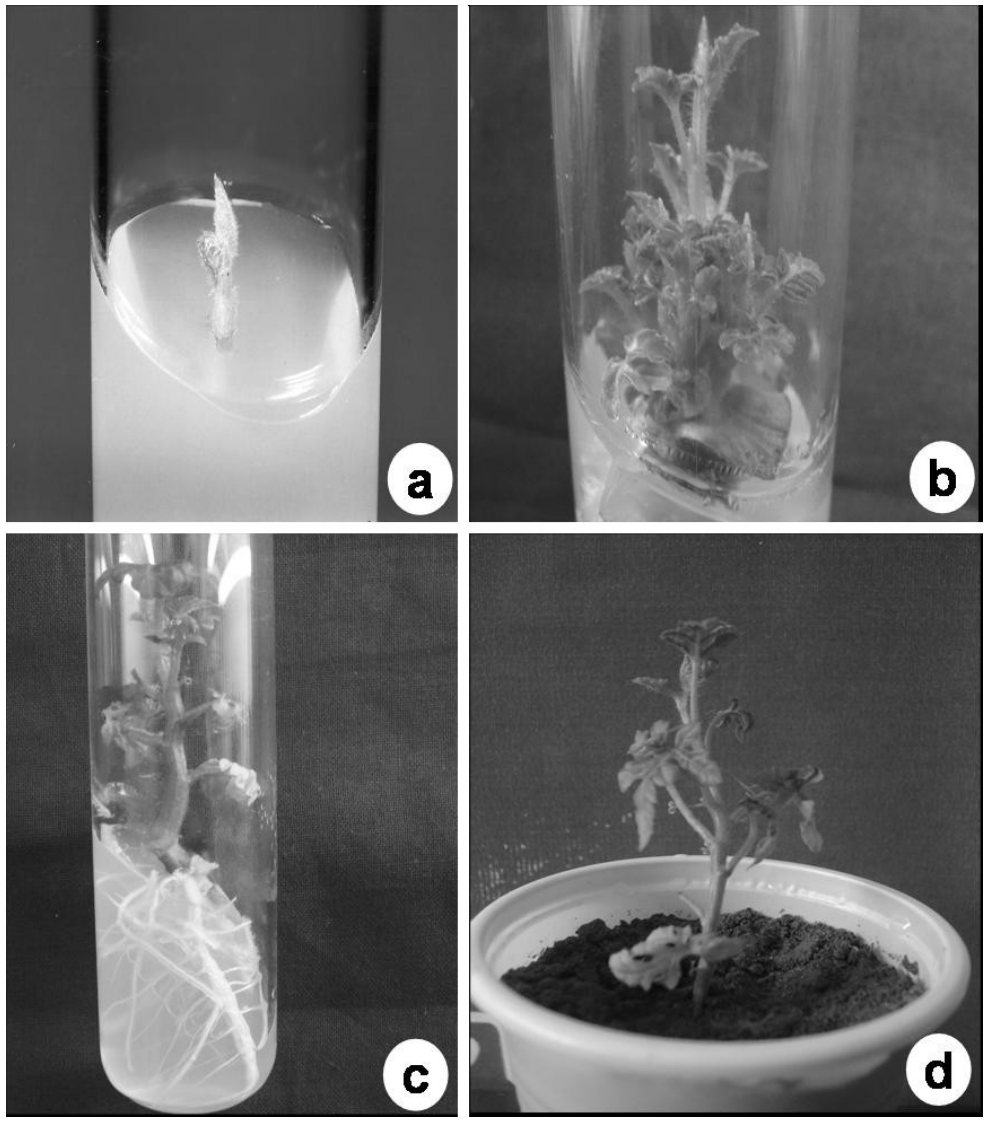

Figure 1 - In vitro clonal propagation of watermelon by axillary shoots proliferation from shoot tips. (a) Inoculation of shoot tip in initial culture medium supplemented with $5 \mathrm{mg} \mathrm{l}^{-1} \mathrm{BA}$ and $0.1 \mathrm{mg} \mathrm{l}^{-1}$ IAA (b) multiple shoot formation on shoot apices in MS medium supplemented with $2 \mathrm{mg} \mathrm{l}^{-1} \mathrm{BA}$, after 5 weeks in culture, (c) adventitious root induction on MS medium containing $1 \mathrm{mg} \mathrm{l}^{-1}$ IBA, after 3 weeks in culture, (d) a potted plant showing growth under ex vitro condition at the $3^{\text {rd }}$ weeks of transfer. 
An average multiplication rate of 4-5-folds per subculture was obtained at an interval of five weeks. Root induction was more prominent in the medium containing NAA $\left(0.5 \mathrm{mg} \mathrm{l}^{-1}\right)$ or IBA $(1.0$ $\mathrm{mg}^{-1}$ ) alone. Shoots from initial cultures and those from subsequent subcultures were rooted (Fig. 1c) on rooting medium and best result was observed in MS medium containing $1.0 \mathrm{mg} \mathrm{l}^{-1} \mathrm{IBA}$ (Table 3). Maximum (100\%) rooting with 12 roots per shoot was recorded in this medium when shoots from second subculture were used. The shoots and were more prone to rooting by increasing the subcultures. IBA is one of the most commonly used plant growth regulator for root induction in watermelon (Krug et al. 2005) and other cucurbits, including summer squash (Pal et al. 2007), ash gourd (Thomas and Sreejesh, 2004) and interspecific hybrid of Cucurbita (Sarowar et al. 2003). In vitro-rooted plantlets were transferred to soil pot for acclimatization (Fig. 1d), and then exposed to natural environmental condition. About $72 \%$ of the regenerated plants survived and showed normal growth. This practice of acclimatization confirmed earlier studies.

Table 3 - Effect of different concentration of NAA and IBA on rooting from regenerated shoot of Citrullus lanatus. Data were collected after 21 days of culture.

\begin{tabular}{ccccc}
\hline $\begin{array}{c}\text { Growth regulators } \\
\left(\mathbf{m g ~ I}^{\mathbf{1}}\right)\end{array}$ & $\begin{array}{c}\text { Days to root } \\
\text { initiation }\end{array}$ & $\begin{array}{c}\text { Rooting frequency } \\
(\mathbf{\%})\end{array}$ & $\begin{array}{c}\text { No. of } \\
\text { roots/shoot }\end{array}$ & $\begin{array}{c}\text { Root length } \\
(\mathbf{c m})\end{array}$ \\
\hline NAA & & & & \\
\hline 0.1 & $20-21$ & 30 & 3.0 & 3.4 \\
0.2 & $10-12$ & 50 & 6.1 & 4.2 \\
0.5 & $8-9$ & 80 & 9.0 & 6.0 \\
1.0 & $10-11$ & 60 & 6.7 & 6.1 \\
1.5 & $15-20$ & 50 & 4.8 & 3.5 \\
\hline IBA & & & & \\
\hline 0.1 & $20-22$ & 50 & 4.5 & 4.5 \\
0.5 & $10-11$ & 57 & 7.0 & 4.9 \\
1.0 & $7-8$ & 100 & 12.0 & 7.0 \\
1.5 & $9-10$ & 80 & 11.0 & 6.0 \\
2.0 & $15-20$ & 70 & 6.5 & 3.7 \\
\hline
\end{tabular}

\section{CONCLUSION}

The results of the present investigation showed a reproducible and efficient plant regeneration system through axillary and adventitious shoots proliferation from shoot apices of watermelon. The protocol could be potentially useful when production of hybrid seeds is not feasible owing to technical difficulties or high production cost. In addition, this regeneration system could be used in the production of transgenic watermelon plants and micropropagation of elite hybrids of seedless watermelon by shoot tip culture. This would allow fixing hybrid vigor and polyploidy parental lines. Therefore, it may reduce the cost of producing hybrid seedlings.

\section{REFERENCES}

Alam I, Sharmin SA, Naher MK, Alam MJ, Anisuzzaman M, Alam MF. Effect of growth regulators on meristem culture and plantlet establishment of sweetpotato (Ipomoea batatas (L.) Lam.). Plant Omics. 2010a; 3: 35-39.

Alam MJ, Alam I, Sharmin SA, Rahman MM, Anisuzzaman M. Alam MF. Micropropagation and antimicrobial activity of Operculina turpethum (Syn. Ipomoea turpethum), an endangered medicinal plant. Plant Omics. 2010b; 3: 40-46.

Alam I, Sharmin SA, Mondal SC, Alam MJ, Khalekuzzaman M, Anisuzzaman $\mathrm{M}$, et al. In vitro micropropagation through cotyledonary node culture of castor bean (Ricinus communis L.) Aust J Crop Sci. 2010c; 4: 81-84.

Chaturvedi R, Bhatnagar S. High-frequency shoot regeneration from cotyledon explants of watermelon cv. sugar baby. In vitro Cell Dev Biol-Plant. 2001; 37: 255-258. 
Compton ME, Gray DJ. Shoot organogenesis and plant regeneration from cotyledon of diploid, triploid and tetraploid watermelon. J Amer Soc Hort Sci. 1993; 118: 151-157.

Compton ME, Gray DJ, Gaba VP. Use of tissue culture and biotechnology for the genetic improvement of watermelon. Plant Cell Tiss Org Cult 2004; 77: 231243.

Dibax R, Quisen RC, Bona C, Quoirin M. Plant regeneration from cotyledonary explants of Eucalyptus camaldulensis Dehn. and histological study of organogenesis in vitro. Braz Arch Biol Technol. 2010; 53: 311-318.

Dong JZ. Jia SR. High efficiency plant regeneration from cotyledons of watermelon (Citrullus vulgaris Schrad). Plant Cell Rep. 1991; 9: 559-562.

Edwards AJ, Vinyard BT, Wiley ER, Brown ED, Collins JK, Perkins-Veazie P, et al. Consumption of watermelon juice increases plasma concentrations of lycopene and beta-carotene in humans. J Nutr. 2003; 133: 1043-1050.

Fang YZ, Yang S, Wu G. Free radicals, antioxidants and nutrition. Nutrition. 2002; 18: 872-879.

Krug MGZ, Stipp LCL, Rodriguez APM Mendes BMJ. In vitro organogenesis in watermelon cotyledons. Pesq agropec bras. 2005; 40: 861-865.

Mayne ST, Cartmel B, Lin H, Zheng T, Goodwin WJJr., Low plasma lycopene concentration is associated with increased mortality in a cohort of patients with prior oral, pharynx or larynx cancers. $J$ Am Coll Nutr. 2004; 23: 34-42.

Moerman DE. Native American ethnobotany. Timber Press Inc. Portland; 1998.

Mohanty NK, Saxena S, Singh UP, Goyal NK, Arora RP. Lycopene as a chemopreventive agent in the treatment of high-grade prostate intraepithelial neoplasia. Urol Oncol. 2006; 23: 383-385.

Murashige T, Skoog F. A revised medium for rapid growth and bioassays with tobacco tissue cultures. Physiol Plant. 1962; 15: 473-497.
Pal SP, Alam I, Anisuzzaman M, Sarker KK, Sharmin $\mathrm{SA}$, Alam MF. Indirect organogenesis in summer squash (Cucurbita pepo L.). Turk J Agric For. 2007; 31: 63-70.

Patil B. Watermelon may have viagra-effect. ScienceDaily [internet]. 2008 [accessed Jan 01, 2011]. Available in: http://www.sciencedaily.com/releases/ 2008/06/080630165707.htm.

Perkins-Veazie P, Collins JK, Davis AR, Roberts W. Carotenoid content of 50 watermelon cultivars. $J$ Agric Food Chem. 2006; 54: 2593-2597.

Radmann EB, Bianchi VJ, Fachinello JC, Ferreira LV, Oliveira RPD. In vitro multiplication of 'Flordaguard' rootstock: cytokinin source and concentration effects, explants orientation and period of permanence in the culture medium. Braz Arch Biol Technol. 2011; 54: 25-34.

Rimando AM, Perkins-Veazie PM, Determination of citrulline in watermelon rind. J Chromatogr A. 2005; 1078: 196-200.

Sarowar S, Oh HY, Hyung NI, Min BW, Harn CH, Yang SK, et al. In vitro micropropagation of a Cucurbita interspecific hybrid cultivar- a root stock plant. Plant Cell Tiss Org Cult. 2003; 75: 179-182.

Thomas TD, Sreejesh KR. Callus induction and plant regeneration from cotyledon explants of ash gourd (Benincasa hispida L.). Sci Hort. 2004; 100: 359-367.

Ulisses C, Camara TR, Willadino L, de Albuquerque $\mathrm{CC}$, de Brito JZ. Early somatic embryogenesis in Heliconia chartacea Lane ex Barreiros cv. Sexy Pink ovary section explants. Braz Arch Biol. Technol. 2010; 53: 11-18.

Zhao X, Aldini G, Johnson EJ, Rasmussen H, Kraemer $\mathrm{K}$, Woolf H, et al. Modification of lymphocyte DNA damage by carotenoid supplementation in postmenopausal women. Am J Clin Nutr. 2006; 83: 163-169. 